\title{
An Evaluation of the Relationships between Personality Traits, Job Satisfaction and Job Performance: An Empirical Study of Jordanian Hospitals
}

\author{
Nayel Mousa Rababah* \\ Department of Business Administration, Jazan University, Jazan, Saudi Arabia
}

DOI: $10.36348 /$ sjbms.2019.v04i11.004 $\quad$ | Received: 08.11.2019| Accepted: 16.11 .2019 | Published: 28.11 .2019

*Corresponding author: Nayel Mousa Rababah

\section{Abstract}

The aim of this study is to examine the effects of personality traits (Big-Five personality) on both job satisfaction and job performance, and to evaluate how job satisfaction affects job performance in the case of the hospital sector. The collected data from 1200 employees in 52 hospitals in Jordan was analyzed, using structural equation modeling. The study finds out that the conscientiousness, extraversion, agreeableness, and openness traits exert positive effects, while neuroticism personality produces a negative effect on job satisfaction. Further, personality traits have a significant correlation with job performance. Job satisfaction has also significant effects on job performance. The empirical analyses yield results consistent with these arguments, personality traits assessed as predictors of job satisfaction and job performance. This study provides guidelines for the hospital sector to emphasize the attribute of employees that could affect and enhance their job satisfaction and performance. Implications for research and practice are correspondingly discussed.

Keywords: Personality traits, job satisfaction, job performance, public hospitals, private hospitals.

Copyright @ 2019: This is an open-access article distributed under the terms of the Creative Commons Attribution license which permits unrestricted use, distribution, and reproduction in any medium for non-commercial use (NonCommercial, or CC-BY-NC) provided the original author and source are credited.

\section{INTRODUCTION}

Every organization is interested in bringing about a superior level of performance from employees. However, the literature has revealed the relationships between personality composition and its performance outcomes in the workplace [1]. According to Mullins [2], the level of job satisfaction is affected by social, personal, cultural, environmental, and organizational factors. Conversely, personality has shown that people's personality determines how they react to the environment and employee performance. "... Personality is a stronger predictor of typical performance because the personality-based behaviors of effort and choice are more constrained in maximum performance contexts" [3]. Despite the progress, prior studies nonetheless have almost focused on the organizational consequences of people demographics.

Equally, studies have shown that there is a relationship between personality and job satisfaction [4, 5]; it comes to influencing the experience of job satisfaction. Templer [6] exposes possible causal explanations of this relation as a result of analyzing recent research in the professional literature; on one hand, a certain personality pattern influences selecting a specific job. On the other hand, the personality profile influences the reaction mean itself (emotional, behavioral) of the individuals to working conditions [7].

Further, "Job satisfaction is a frequently used construct studied in the organizational psychology, being considered to have a direct influence on the working quality of the employees of an organization" [7]. Spector [8] also asserts that job satisfaction is the extent to which people like (satisfaction) or dislike (dissatisfaction) their jobs. Conversely, the effectiveness of competitive advantage mainly depends on the performance of the workforce. Job performance concerns the knowledge, skills, and attitudes that are required to enable an individual to perform the activities listed in the job description. At the same time, studies 
have shown that working personality compositions is also related to the satisfaction of an individual $[6,7]$.

The objectives of this study are to constantly try identifying the personality traits that interrelate with the satisfaction in order to establish the level of influence of these traits and satisfaction over job performance of workers. By collecting a sample from firms in Jordan, using the structural equation model (SEM), the fundamental idea of the study is to build an integrated intellectual framework that sets out the goals and mechanisms to achieve, in connection with the distinguished performance. The study sheds light on the importance of the personality traits to enhance job satisfaction and then promotes the high performance of workers.

The study contributes to the performance contexts and personality traits literature by examining the deep-level cognitive dynamics of employees and their effects on job performance. The researcher utilizes the well-known Five-Factor (or Big-Five) Model [9], which characterizes a person's personality with five types of psychometric attributes which is the basis of explaining job satisfaction and identify the personality discrepancies of employees performance. Performance appraisal is used in organizations worldwide as a means to ensure the (at least) adequate performance of employees. Job performance can also be achieved when the employees meet the expectation of the employer and are attributable to the company's success.

\section{Theoretical background \& hypotheses development Theoretical Background}

\section{Personality Traits/ Big-Five Model}

Over the last 5 decades, personality psychologists have proposed a number of classification schemes aimed at organizing the universe of personality variables and measures into a limited and conceptually sound taxonomy [10]. The big-five model (FFM) brings together over 40 years of research on the emotional, interpersonal, experiential, attitudinal, and motivational styles of an individual [11].

Almost all of personality measures can be located on FFM or Big-five [12]. FFM had been examined as the highly generalizable and stable [9], applicable to various cultures [5], and universally accepted personality traits model [12]. The study utilizes the well-known Five-Factor (or Big-Five) Model, which characterizes a person's personality with five types of psychometric attributes, to identify the personality of employees. FFM include, five personality dimensions: extraversion, conscientiousness, agreeableness, openness to experience, and neuroticism/emotional stability [9], although a number of studies concern significant and generalizable relationships between each dimension of the five-factor model and either leadership emergence or effectiveness [13].

The researcher chooses this five-factor model as considered attributes that are deemed to capture the degree of significance in a firm's employee's behavior, and numerous studies found that behaviors correlate with corresponding personality traits [14]. However, the five-factor model provides a parsimonious yet comprehensive taxonomy of personality. The study focuses on the average level, rather than the deviation, of employees' personality traits, and each personality dimension describes a broad domain of psychological functioning that is composed of a set of more specific and narrow traits [11].

\section{Job Satisfaction}

Job satisfaction is the most considerable factor in understanding the worker motivation, effectiveness and performance. Job satisfaction is a key issue for health care professionals around the world $[15,16]$. In the past, most job satisfaction research attempted to use employees' overall attitude toward a job to predict one or two specific behaviors such as output or absenteeism, but the job satisfaction is providing incremental validity in the prediction of employee performance beyond what is currently possible for knowledge, skills, or abilities of employees [17-18]. Job satisfaction describes a positive feeling about a job, resulting from an evaluation of its characteristics. A person with a high level of job satisfaction holds positive feelings about his or her job, while a person with a low level holds negative feelings [19].

However, Spector [8] stated that the antecedents of job satisfaction can be categorized into two groups: The first group includes the job environment itself and some factors related to the job. The second group includes individual factors related to the person, who will bring these factors to the job including previous experiences and personality. George and Brief [20] also indicated alternative conceptualizations of job satisfaction and/or job performance; this model explained how positive attitudes toward one's job could predict a high degree of job performance.

There is no universally accepted definition of job satisfaction because it is a complex and multifaceted concept that provides different definitions and perceptions of different individuals. Armstrong [21] defined job satisfaction as the feelings and attitudes of people toward their job; it is a positive emotional state resulting from the appraisal of one's job or job experiences. Workers who have a high level of job satisfaction generally love their job. Job satisfaction as a feeling (approach or avoidance emotion) an employee has about his work, pay, promotional opportunities, supervisor, and co-workers [22]. While George and Jones [23] indicated, individual's general attitude 
toward his or her job. A person with a high level of job satisfaction holds a positive attitude about the job, while a person who is dissatisfied with his or her job holds negative attitudes about the job. Then, job satisfaction may be defined as a positive feeling about a job resulting from an evaluation of its characteristics [19].

Conversely, various authors have identified the different factors that influenced job satisfaction. Job satisfaction can be divided into five facets using the job descriptive index (JDI) [24] these are pay, promotion, co-workers, supervision, and work. And they include but not limited to salaries and benefits, organizational climate, autonomy, achievement, recognition, job security, workplace flexibility, degree of professionalism, communication, working conditions, interpersonal relationships and job importance [25, 18].

\section{Job Performance}

Performance has been conceptualized from two perspectives: Process (or an action) and outcome [26, 27, 17]. Process concerns the process aspect (e.g. behavioral), the behavioral aspect refers to what people do while at work, the action itself. In this vein, Campbell, et al. [17] outline eight factors that should account for all of the behaviors that are encompassed by job performance (i.e., job-specific task proficiency, non-job-specific task proficiency, written and oral communication task proficiency, demonstrating effort, maintaining personal discipline, facilitating peer and team performance, supervision/leadership, and administration). While the outcome is a constellation of outcome aspect, in turn, refers to the result of the individual's behavior [28]. Job performance is suggested to be related to the observable behaviors that people do in their jobs that are relevant to the goals of the organization.

Furthermore, job performance has been indicated about work performance and was intended to explain individual differences in career success [14]. Job performance in the workplace is valuable and interest for employees and organizations to increased satisfaction which is suggested to be related to the increased productivity (outcome). When looking at the relationship between job satisfaction and job performance, which suggests that attitudes regarding a behavior lead to intentions to perform, and then to actual performance (outcome) of the behavior.

\section{Hypotheses Development \\ Personality Traits and Job Satisfaction}

Job satisfaction is influenced by both employees' personality profile and the manager's leadership style and implicitly, by the team leader's personality [29, 7]. Researchers have related personality with job satisfaction, and its prediction of employee behavior and their performance [30]. People with positive attitudes towards their job mean job satisfaction, but if they have negative attitudes towards their job, this means job dissatisfaction.

Research has shown that openness can increase social interaction [31]. As a consequence, people with high openness traits will feel empowered to resolve problems or conflicts with flexible [32], promote communication and cooperation and hence, increase job satisfaction and a high level of outcome performance. However, individuals with higher openness to experience scores more likely to be satisfied with jobs that involve innovation and learning new skills [33].

Agreeableness is characterized by being helpful, altruistic, and generally cooperative. These traits are theoretically associated with positive helping behaviors that advance for high performance [32]. Agreeable individuals tend to engage in more teamwork, are more cooperative, and have higher quality interpersonal interactions [34]. When looking at agreeableness and its effect on satisfaction and performance, high agreeableness individuals have positive feelings about themselves and are able to perform better because of this. So, people who are high in agreeableness would encourage especially cohesive, promote communication, cooperation and hence, increase their job performance.

Conscientiousness includes a volitional component that is related to achieve self-motivation, and efficaciousness [35], which would lead to higher levels of job satisfaction and employee performance to complete their work tasks. Conscientiousness leads to higher levels of job satisfaction because highly conscientious people tend to respond favorably to the rules inherent in organizations [36]. People who are also high in conscientiousness tend to be dependable, careful, thorough, responsible, and organized ones [31], which would increase job levels of satisfaction and performance.

Extraverted people like to socialize and teamwork with others, and like to people's energy level, potency, and positive affectivity [32], which would lead to higher levels of job satisfaction. Research has shown that extraverted people are more comfortable, skilled in communicating, and cooperative behavior [34, 35]. If extraversion employees are at their job, they will likely be satisfied, because extraverts have higher levels of social interaction in the workplace which could increase their satisfaction as well as their performance [1].

Neuroticism is described by Costa and McCrae [9] as being distressed, nervous, irrational, and impulsive. Emotional stability has been one of the strongest dispositional predictors of job satisfaction [4]. Employees who are high in neuroticism are more likely to uncooperative in work. At the same time, people who are low in emotional stability have exaggerated responses to rewards [37]. It is also expected that 
employees who score low on neuroticism are more likely to engage and enjoying work, which would lead to higher levels of job satisfaction and performance.

Furthermore, many researchers have begun to give a considerable amount of attention to the effect of personality traits on job performance. As some researchers indicated, a large proportion of the job satisfaction literature has assumed that satisfaction at work is a function of either the dispositional characteristics (personality) or situational factors job characteristics [38]. However, recent research findings suggest and support the simultaneous study of the influences of both the personality and job characteristic factors on job satisfaction [39]. Crewson [40] found that public sector employees rate a feeling of accomplishment and performing work helpful to society and to others as more important job characteristics than do private-sector employees.

However, personality traits in terms of conscientiousness can promote task-specific selfefficacy beliefs, which can be organized to achieve team goals, and affect task cohesion [41]. People with high personality (c.f., agreeableness) encourage work together and will feel empowered, through the decentralization of power [42], which enhances members' shared decisions, and motivation to perform well. Conversely, people who are emotionally stable (low in neuroticism) may contribute positively to teamwork, and make suggestions for change because they do not feel helpless [34]. As a result, job satisfaction is a pleasurable or positive emotional state resulting from the appraisal of one's job or job experiences [34], and promotes communication and cooperation and hence, increases job performance. Consequently, the following hypotheses are proposed:

H1a. Openness to experience in the term of personality traits will be positively associated with job satisfaction.

H1b. Agreeableness in the term of personality traits will be positively associated with job satisfaction.

H1c. Conscientiousness in the term of personality traits will be positively associated with job satisfaction.

H1d. Extraversion in the term of personality traits will be positively associated with job satisfaction.

H1e. Neuroticism in the term of personality traits will be negatively associated with job satisfaction.

H2. There is a significant correlation between personality traits and job performance.

\section{Job Satisfaction and Job Performance}

Several studies had been conducted to investigate the relationship between job satisfaction and performance whether individually, in work groups and organizations [44, 45, 46], and the most important variable in predicting employee behavior [47]. Ostroff [48] found that organizations with more satisfied employees tended to be more effective than organizations with employees dissatisfied.

Workers who have a high level of job satisfaction generally love their job; they feel that their job gives them some positive features such as challenge, autonomy, and creation, etc. These workers will have extraordinary performance, and the companies with these kinds of workers will be successful. Bruce and Blackburn [49] presented the fact of a positive relationship between job satisfaction and job performance. Spector [8] also pointed out the potentiality of a performance-satisfaction relationship is evidence supported the positive relationship between job satisfaction and job performance.

As several studies have concluded, happy workers are more likely to be productive workers. Organizations with more satisfied employees tend to be more effective than organizations with few [19]. Naff and Crum [50] found a significant relationship between public service motivation and federal employees' job satisfaction, job performance, intention to remain in the government. It seems to be a common assumption that employees, who are happy with their job, should also be more productive at work. Job satisfaction simply explains the attitude of employees toward their job. Satisfied employees have a positive attitude, toward job which leads to high-performance level, whereas dissatisfied employees have a negative attitude, toward work which yields low-performance result. The following hypothesis is proposed:

\section{H3. There is a significant positive relationship between} Job Satisfaction and Job Performance

\section{RESEARCH DESIGN AND METHODOLOGY}

\section{Research Design and Sample Selection}

The research sample is drawn from Jordan. According to Jordan Investment Commission [51], the Jordanian healthcare sector is known for its high-quality services, both regionally and internationally, due to the presence of world-class internationally qualified medical workforce and accredited hospitals and facilities equipped with state-of-the-art medical machinery and equipment.

The healthcare sector in Jordan is featured with sound policies and enabling regulations for business operators and investors alike: the infrastructure is solid and the national policies customized to healthcare operations and cutting-edge technologies both empower Jordan's business environment for guaranteeing a prosperous healthcare sector.

The competitiveness of Jordan's healthcare sector specifically revolves around the highly skilled workforce as the sector benefits from the availability of 
over 57,000 well-trained medical staff, in combination with comparatively low treatment fees. Jordanian professionals in the healthcare sector are also highly sought after based on their solid education, training, qualification, and creativity. Jordan has the largest pool of physicians, dentists, and nurses per capita compared to the region $[51,52]$.

Further, the health care system in Jordan consists of two main sectors: the public/semipublic sector and the private sector. Both sectors include hospitals, primary care clinics, pharmacies, and other ancillary services. In other words, providers of the health care systems are the Ministry of Health, Royal Medical Services, University Hospitals (Jordan University Hospital \& King Abdullah University Hospital) and the private sector. There are a total of 110 hospitals in Jordan, as 62 private and 48 public hospitals providing 27.462 beds [51, 52].

For the Jordanian sample, the final usable sample includes 1200 employees in 52 hospitals. An average firm (hospital) age is 17 years (s.d.= 14.60). About $40 \%$ of hospitals are in the public sector and $60 \%$ in the private sector. Participant workers consisted of an average age is 27 years (s.d.=6.44), and had 11.12 (s.d.=5.20) years of experience in their firm's industry. Further, $65 \%$ of the sample was married. Participant workers consisted of women in the amount of $55.2 \%$, and men in the amount of $44.8 \%$. As for the education levels of the participants, $4 \%$ had a high school or below, $36.5 \%$ had a college degree, $52.5 \%$ had a bachelor degrees, and $7 \%$ had a master degree or above.

\section{Measurements of Variables \\ Independent Variables}

Personality Traits: Personality traits are assessed with the Big-Five personality attributes. The 7point Likert-type $(1=$ strongly disagree; $7=$ strongly agree) International Personality Item Pool (IPIP) measure developed by Goldberg [53] was used to assess employees' Big-Five personality attributes. Respondents are asked how they would describe themselves. The instrument comprises 50 items designed to reflect five dimensions of personality characteristics (conscientiousness, extraversion, openness to experience, agreeableness, and neuroticism). Each dimension consists of ten items that represent positive and/ or negative aspects of a specific personality. The internal consistency reliabilities for the Five-Factor scales calculated for this study based on these a single scores were: $(\alpha=0.81),(\alpha=0.90),(\alpha=0.88),(\alpha=$ $0.89)$, and $(\alpha=0.92)$ for extroversion, agreeableness, conscientiousness, neuroticism, and openness to experience, respectively. Also, CFA results showed acceptable model fit indices for each of Big-Five personality traits (available from the author).

Job Satisfaction: Job satisfaction (Job Satisfaction Survey JSS) was evaluated by 9-items aspects of job satisfaction used by organizations in training and maintaining valuable staff [54] $(\alpha=.82)$ including pay, promotion, benefits, supervision, operating procedures, co-workers, contingent rewards, nature of work, and communication. Respondents employees' attitude - were asked to indicate the extent of their satisfied, how satisfied are with their current job situation, agreement with each statement on a 7-point Likert-type scale ( 1 = strongly dissatisfied, $7=$ strongly satisfied). CFA results showed the model fitted the data well $\left(\chi^{2}=4.40, \mathrm{df}=5\right.$; NNFI $=.95, \mathrm{CFI}=.96, \mathrm{SRMR}=$ $.04, \mathrm{RMSEA}=.03)$.

\section{Dependent Variable}

Job performance: A 5-item, 7-point Likert-type ( $1=$ strongly disagree; $7=$ strongly agree) scale was developed by Pearce and Porter [55] and used by Carmeli and Freund [56]. Cronbach's $\alpha$ for the overall scale was (.95). Respondents were asked to indicate the extent of their work agreement with each statement, such as the ability to get along with others, the achievement of work goals, and complete task on the time, quality of performance and overall performance. CFA results showed acceptable model fit indices $\left(\chi^{2}=\right.$ $3.2, \mathrm{df}=2 ; \mathrm{NNFI}=.97, \mathrm{CFI}=.98, \quad \mathrm{SRMR}=.02$, RMSEA= .04).

\section{Control Variables}

Control Variables: To decrease the likelihood of spurious results, several control variables are added to the model [35]. The study controlled for variables that may affect job satisfaction and job performance, including employees information (i.e. average age, experience, education \& FFM personality heterogeneities), industry-level variables (i.e. environmental dynamism and munificence), and firmlevel characteristics (i.e. age, and organizational slack) [57].

\section{STATISTICAL ANALYSIS}

Structural equation modeling (SEM) can closely examine the relationships between observed indicators and latent variables while simultaneously controlling for measurement errors. A two-step structural equation modeling approach [32] implemented in AMOS 16.0 is performed to evaluate the models and test the hypotheses. The first step is to fit a confirmatory factor analysis (CFA) to check for convergent and discriminate validity, to confirm the full measurement model, and then test a series of structural models to test the hypotheses. To assess model fit, the chi-square $\chi^{2}$ test was used, and four additional fit indices, including comparative fit index (CFI), nonnormed fit index (NNFI), root-mean-square error of approximation (RMSEA), and standardized root-meansquare residual (SRMR),were applied to assess model fit [58]. 


\section{RESEARCH ANAL YSIS AND RESULTS} Structural Models, Hypotheses Testing and Results

Table 4.1 presents the means, standard deviations and correlations for the variables examined in the study. Table 4.2 presents the value of fit indices for the examination of various structural models. To determine whether the big five personality traits individually presented a direct relationship with job satisfaction and job performance, two rival models were tested separately, five paths were tested by separately adding personalities-job satisfaction relationship Model 2 to the hypothesized fully model, and Model 3 presented personalities-job performance. Significant relationship between personality traits with job satisfaction and job performance $\left(\chi^{2}=374.22, \mathrm{df}=139\right.$, $\mathrm{p}<.001 ; \quad \mathrm{CFI}=.91, \quad \mathrm{NNFI}=.91, \quad \mathrm{RMSEA}=.04$ and $\mathrm{SRMR}=.03)$, and $\left(\chi^{2}=358.94, \mathrm{df}=133, \mathrm{p}<.001\right.$; $\mathrm{CFI}=.90$, NNFI=.92, RMSEA=.04 and $\mathrm{SRMR}=.03$ ) respectively. Taken together, the researcher obtained
Model 4 as the final model including personality traits, job satisfaction and job performance $\left(\chi^{2}=332.47\right.$, $\mathrm{df}=128, \mathrm{p}<.001 ; \mathrm{CFI}=.91, \mathrm{NNFI}=.92$, RMSEA $=.04$ and $\mathrm{SRMR}=.04)$. The result suggested that the model indeed fit the index.

Figure 4.1 presents the completely standardized path estimates for the examined relationships. Consistent with expectations, conscientiousness $(\beta=.22)$, extraversion $(\beta=.18)$, openness to experiences $(\beta=.33)$, and agreeableness $(\beta=$ .20) were all positively, while neuroticism $(\beta=-.28)$ was negatively related to job satisfaction (all p's $<.05$ ), supporting H1a-H1e. Personalities traits were positively associated with job performance $(\beta=.15, \mathrm{p}<.001)$, supporting H2. Also, job satisfaction was positively related to job performance, supporting $\mathrm{H} 3(\beta=.35, \mathrm{p}<$ $.001)$.

Table-4.1: Means, Standard Deviations, and Correlations

\begin{tabular}{|c|c|c|c|c|c|c|c|c|c|c|c|c|c|c|c|c|}
\hline Variables & $\mathbf{M}$ & SD & 1 & 2 & 3 & 4 & 5 & 6 & 7 & 8 & 9 & 10 & 11 & 12 & 13 & 14 \\
\hline 1. Extraversion $\mathrm{P}$ & 4.70 & 1.55 & & & & & & & & & & & & & & \\
\hline 2. Agreeableness $\mathrm{P}$ & 4.90 & 1.61 & .04 & & & & & & & & & & & & & \\
\hline 3. Neuroticism $P$ & 3.75 & 1.37 & -.05 & .04 & & & & & & & & & & & & \\
\hline 4. Conscientiousness P & 5.51 & 1.65 & .07 & -.10 & .10 & & & & & & & & & & & \\
\hline 5. Openness P & 4.41 & 1.45 & -.08 & .10 & .20 & .03 & & & & & & & & & & \\
\hline 6. Job satisfaction & 5.75 & 1.80 & $.22 *$ & $.20 * *$ & $-.12 *$ & $.22 * *$ & $.39 *$ & & & & & & & & & \\
\hline 7. Job performance & 4.50 & 1.50 & $.15^{*}$ & $.23 * *$ & $.30 *$ & $.25 * *$ & $.35^{*}$ & $.41 * *$ & & & & & & & & \\
\hline 8. Employees age & 1.61 & 0.39 & .07 & .04 & .11 & .12 & .06 & .09 & .06 & .12 & & & & & & \\
\hline 9. Employees education $\mathrm{H}$ & 0.56 & 0.31 & .04 & .11 & -.13 & .14 & .17 & .10 & .06 & .00 & & & & & & \\
\hline 10. Employees experience & 11.12 & 5.20 & .01 & -.09 & -.11 & .12 & .16 & $.18^{*}$ & .11 & .06 & .06 & & & & & \\
\hline 11. Firm age & 1.12 & 0.40 & .05 & .10 & .11 & -.11 & .12 & .16 & $.08^{*}$ & .01 & .18 & .02 & & & & \\
\hline 12. Firm slack & 5.10 & 1.70 & -.04 & .04 & -.00 & .04 & -.11 & .12 & $.06^{*}$ & .19 & .06 & $.16^{*}$ & .02 & & & \\
\hline 13. Environmental munificence & 4.90 & 1.65 & -.03 & -.09 & .02 & .02 & .12 & -.11 & $.12 * *$ & .06 & .21 & .01 & .03 & .03 & & \\
\hline 14. Environmental dynamism & 5.50 & 1.77 & .06 & .01 & .06 & .12 & .21 & .07 & $-.20 *$ & $.21 *$ & .23 & -.13 & .07 & $.14^{*}$ & .10 & \\
\hline
\end{tabular}

Note: $\mathrm{N}=1200,{ }^{* * *} \mathrm{p}<.01,{ }^{*} \mathrm{p}<.05 ; \mathrm{P}=$ personality; $\mathrm{H}=$ heterogeneity

Table-4.2: Structural Models- fit index model

\begin{tabular}{|l|l|l|l|l|c|c|}
\hline \multicolumn{1}{|c|}{ Models } & $\chi^{2}$ & df & NNFI & CFI & SRMR & RMSEA \\
\hline 1. Hypothesized model & $433.45^{* * *}$ & 156 & .90 & .90 & .05 & .05 \\
\hline 2. Personality traits $\rightarrow$ Satisfaction & $374.22^{* * *}$ & 139 & .91 & .91 & .03 & .04 \\
\hline 3. Personality traits $\rightarrow$ Performance & $358.94 * * *$ & 133 & .92 & .90 & .03 & .04 \\
\hline 4. Personality traits $\rightarrow$ Satisfaction $\rightarrow$ Performance & $332.47 * * *$ & 128 & .92 & .91 & .04 & .04 \\
\hline
\end{tabular}

Note: $* * * p<.001$

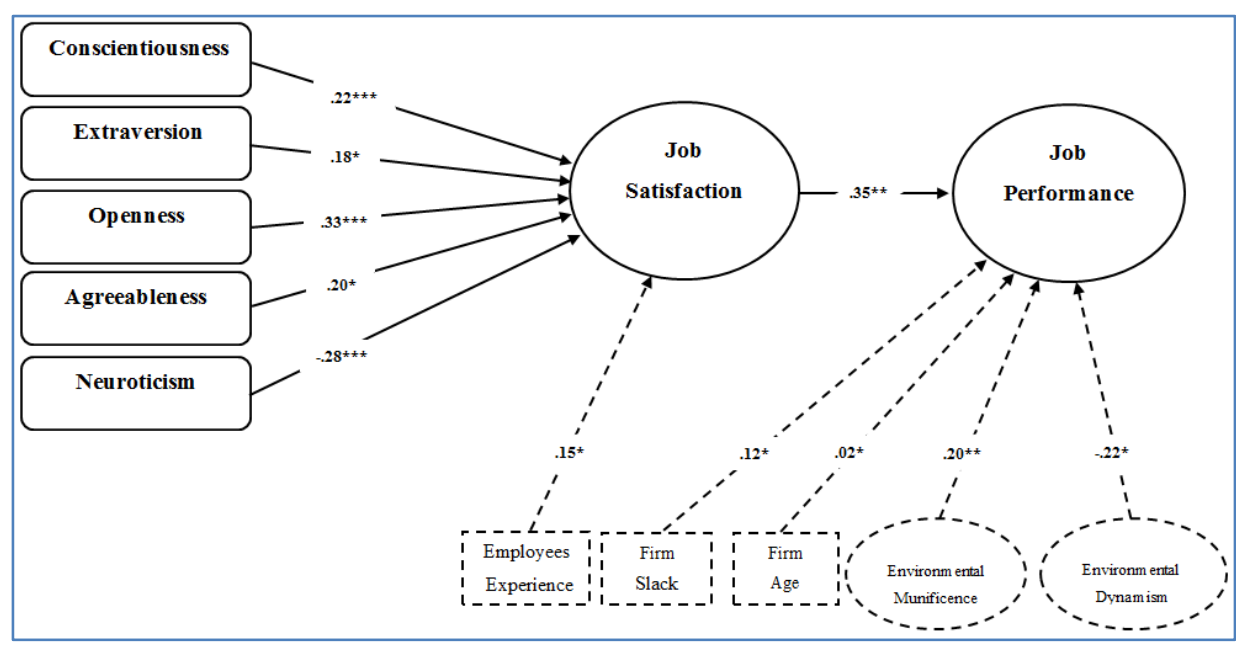

Fig-4.1: Completely Standardized Estimates of the Final Model 
Note: 1.This is a simplified version of the examined model. The direct links between personality traits and job performance are omitted. The observed indicators, measurement errors, explained variances of latent factors, and correlations between exogenous factors are also not included in the figure.

2. Control variables are depicted by dash line.

3. The path coefficients are standardized parameter estimates. $\mathrm{N}=1200,{ }^{*} \mathrm{p}<.05,{ }^{* *} \mathrm{p}<.01$, $\mathrm{p}<.001$.

\section{DISCUSSION, CONCLUSIONS AND FUTURE RESEARCH \\ Research Discussion}

This study examines the relationships among personality traits (Big-Five personality), job satisfaction and job performance in the case of the hospital's sector in Jordan. Results support the theoretically derived causal model and key hypothesized relationships. The empirical results of this research provided new insight into the analysis of the relationship between personality traits, job satisfaction and job performance. Specifically, employees have higher levels of openness, agreeableness, conscientiousness, and extraversion, as well as a lower level of neuroticism, which will produce a higher level of job satisfaction, which in turn can bring about a higher level of job performance. Moreover, job satisfaction was positively related to job performance.

Personality traits are associated with a high degree of job satisfaction. The results show that personality traits such as extraversion; agreeableness, openness to experience, and conscientiousness have a significant positive relationship with job satisfaction. This indicates that personality traits also have an influence on job satisfaction. Consequently, people should be aware of those personality traits that can discover them to the satisfaction and expose consciously the direction of their behavior, which is an advance high-performance worker.

Further, the current study concluded that experienced employees showed more job satisfaction than less experienced employees. These outcomes are consistent with previous studies $[59,60]$ that indicated tenure had a positive relationship with job satisfaction.

Finally, the third hypothesis sights the effects of job satisfaction addressed to improving the job performance degree of the employees. The result shows a significant positive relationship between job satisfaction and job performance. Job satisfaction is related to other key factors of organizational behavior such as turnover, absenteeism, performance, productivity and its prediction of employee behavior. Therefore, an employee's job satisfaction is the affective state of employees regarding multiple facets of their jobs. Top management teams of hospitals may consider the impact that job characteristics had upon satisfaction with their job. So, in order to institutionalize satisfaction performance in health services, it is critical to ensure that personality, motivation, adequate incentive pay and resources for quality improvement and job performance are aligned and integrated.

\section{RESEARCH IMPLICATIONS}

Personality plays a role in job satisfaction; research has shown that people who have a positive belief in their inner worth and basic competence are more satisfied with their jobs than those with negative estimation. In other words, personality traits would better predict a general behavior, such as whether the employees were engaged in their work or motivated to contribute to their organization. This indicates that the attribute of a job has an influence on satisfaction and performance. However, managers can apply these results to assign jobs based on adapting the personality traits is to be tested with the person who wants to work in hospitals.

Job satisfaction has also significant managerial implications. If job satisfaction is high, the employees will perform better. On the other hand, if job satisfaction is low, there will be performance problems. In examining the outcomes of job satisfaction, employees are satisfied with their work, there are many positive outcomes in the workplace, satisfied workers are more productive, more satisfied, and satisfaction influences organizational citizenship behaviors through perceptions of fairness. Further, satisfied frontline employees increase customer satisfaction and loyalty $[19,36,61,62]$.

One of the main causes of job satisfaction is that jobs provide training; variety, independence, and control that satisfy most employees. There is a strong correspondence between how well people enjoy the social context of their workplace and how satisfied they are overall. At the same time, satisfied employees are moderately less likely to miss work, and satisfied employees are less likely to quit and/ or turnover.

In addition, this study provides some insights for managers, who should realize and consider the importance of the factors (e.g. personality rewards, supervision, pay, communication) which can enhance their employees' level of job satisfaction. Managers also as well as employers realize that for their organization to achieve the best performance, it depends on a part on the employee's level of job satisfaction.

\section{Research Limitations and Future Directions}

One of the limitations of this study is related to the research sample. This research was carried out in Jordan companies that decided to participate in the 
empirical research, and the companies belonging to a particular hospital sector, which means could not to some general conclusions for all of Jordanian companies. Consequently, a limitation of this study is the inclusion of only Jordan from the region, thus the findings may not be generalizable to all countries context. It is important to scale up the study to other countries in the region.

This study also examines the relationship between personality traits, job satisfaction, and job performance. Future studies may try to capture the new variables to assess and access requirements for developing the healthcare (hospitals) sector. Although job satisfaction appears to be relevant across cultures, evidence suggests that employees in Western cultures have higher levels of job satisfaction than those in Eastern cultures [19, 63]. Future research could analyses the impact of job satisfaction also on employees' personality and job outcome performance. Further, research could conduct cross-cultural research to explore the impact of national culture on the issues which have been argued.

In conclusion, the important of personality traits can be considered as the employee's workplace performance. Personality traits were tolerance, flexibility, creativity and achievement of outcome performance. This study has identified a personality trait that is likely to generate satisfaction for the workers and advance high-performance employees. Job performance also refers to the output that person has contributed to the organization concerning his behavior to engage in, and which the organization may perceive as productivity.

\section{REFERENCES}

1. Barrick, M. R., Stewart, G. L., \& Piotrowski, M. (2002). Personality and job performance: Test of the mediating effects of motivation among sales representatives. Journal of Applied Psychology, 87(1), 43-51.

2. Mullins, L. J. (1998). Managing People in the Hospitality Industry. (3rd ed.). Harlow: Addison Wesley Longman Limited.

3. Lim, B.-C., \& Ployhart, R. E. (2004). Transformational leadership: Relations to the fivefactor model and team performance in typical and maximum contexts. Journal of Applied Psychology, 89(4), 610-621.

4. Judge, T. A., Heller, D., \& Mount, M. K. (2002b). Five-factor model of personality and job satisfaction: A meta-analysis. Journal of Applied Psychology, 87(3), 530-541.

5. McCrae, R. R., \& Costa, P. T. J. (1997). Personality trait structure as a human universal. American Psychologist, 52(5), 509-516.

6. Templer, K. J. (2012). Five-Factor model of personality and job satisfaction: The importance of agreeableness in a tight and collectivistic Asian society. Applied Psychology: An International Review, 61(1), 114-129.

7. Mihalcea, A. (2013). The impact of leader's personality on employees' job satisfaction. Procedia - Social and Behavioral Sciences, 78(13), 90 - 94.

8. Spector, P. E. (1997). Job satisfaction: Application, assessment, causes, and consequences. Thousand Oaks, CA: Sage Publications, Inc

9. Costa, P. T. J., \& McCrae, R. R. (1992). Revised NEO personality inventory (NEO-PI-R) and NEO five factor inventories (NEO-FFI) professional manual. Odessa, FL: Psychological Assessment Resources.

10. Barry, B., \& Stewart, G. L. (1997). Composition, process, and performance in self-managed groups: The role of personality. Journal of Applied Psychology, 82(1), 62-78.

11. Zhao, H., \& Seibert, S. E. (2006). The big five personality dimensions and entrepreneurial status: A meta-analytical review. Journal of Applied Psychology, 91(2), 259-271.

12. Goldberg, L. R. (1999). A broad-bandwidth, public domain, personality inventory measuring the lowerlevel facets of several five-factor models. Personality psychology in Europe, 7(1), 728.

13. Judge, T. A., Erez, A., Bono, J. E., \& Thoresen, C. (2002a). Discriminant and incremental validity of four personality traits: Are measures of self-esteem, neuroticism, locus of control, and generalized selfefficacy indicators of a common core construct? Journal of Personality and Social Psychology, 83(3), 693-710.

14. Hogan, R. (1996). A socioanalytic perspective on the five-factor model. In J. S. Wiggins (Ed.), the five-factor model of personality: Theoretical perspectives (pp. 163-179). New York, NY, US: Guilford Press.

15. Doef (van der), M., Mbazzi, F. B., and Verhoeven C. (2012). Job conditions, job satisfaction, somatic complaints and burnout among East African nurses. Journal of Clinical Nursing, 21 (11-12), 1763-1775.

16. Platis, C., Reklitis, P., \& Zimeras, S. (2015). Relation between job satisfaction and job performance in healthcare services. Procedia Social and Behavioral Sciences, 175(12), 480-487.

17. Campbell, J. P., McCloy, R. A., Oppler, S. H., \& Sager, C. E. (1993). A theory of performance. In N. Schmitt \& W. C. Borman (Eds.) Personnel selection in organizations (pp. 35-70). San Francisco, CA: Jossey-Bass.

18. De Loach, R. (2003) Job satisfaction among hospice interdisciplinary team members. American Journal of Hospital Palliative Care, 20(6):434-40.

19. Robbins, S. P., \& Judge, T. A. (2013). Organizational behavior. 15th ed. Pearson.

20. George, J. M., \& Brief, A. P. (1996). Motivational agendas in the workplace: The effects of feelings on focus of attention and work motivation. Elsevier Science/JAI Press. 
21. Armstrong, M. (2003). A Handbook of Human Resource Management Practice. (9th ed.). London: Kogan Page.

22. Milbourn, G., J, \& Haight, T. (2004). Teaching the job satisfaction audit project to business school student. Journal of American Academy of Business, 5(1/2), 353-356.

23. George, J., \& Jones, G. (2002). Organizational Behavior (3rd ed.). Upper saddle river, NJ: Prentic Hall.

24. Vitell, S. J., \& Davis, D. L. (1990). The relationship between ethics and job satisfaction: An empirical investigation. Journal of Business Ethics, 9(6), 498-494.

25. Chu, C. (2003) Job satisfaction of hospital nurses: An empirical test of a causal model in Taiwan. International Nursing Review, 50(1):176-82.

26. Kanfer, R. (1990). Motivation theory and industrial and organizational psychology. Handbook of industrial and organizational psychology, 1(2), 75130.

27. Roe, R. A. (1999). Work performance: A multiple regulation perspective. International review of industrial and organizational psychology, 14, 231336.

28. Borman, W. C., \& Motowidlo, S. M. (1993). Expanding the criterion domain to include elements of contextual performance. Personnel Selection in Organizations; San Francisco: Jossey-Bass, 71.

29. Yun, S., Cox, J., Sims, H., \& Salam, S. (2007). Leadership and teamwork: The effects of leadership and job satisfaction on team citizenship, international Journal of Leadership Studies, 2(3), 171-193.

30. Judge, T. A., Heller, D., \& klinger, R. (2008). The dispositional sources of job satisfaction: A comparative test. Applied Psychology: An International Review, 57(3), 361-372.

31. Barrick, M. R., \& Mount, M. K. (1991). The big five personality dimensions and job performance: A meta-analysis. Personnel Psychology, 44(1), 126.

32. Lin, H. C., \& Rababah, N. (2014). CEO-TMT exchange, TMT personality composition, and decision quality: The mediating role of TMT psychological empowerment. The Leadership Quarterly, 25(5), 943-957.

33. Furnham, A., Eracleous, A., Chamorro-Premuzic, T. (2009) Personality, motivation and job satisfaction: Hertzberg meets the Big Five. Journal of Managerial Psychology, 24(8) 765 - 779.

34. LePine, J. A., \& Van Dyne, L. (2001). Voice and cooperative behavior as contrasting forms of contextual performance: Evidence of differential relationships with big five personality characteristics and cognitive ability. Journal of Applied Psychology, 86(2), 326-336.

35. Rababah, N. M. (2017). The interface between CEO-TMT and its effects on the firm performance.
The International Journal of Business \& Management, 5(11), 32-46.

36. Organ, D. W., \& Ryan, K. (1995). A meta-analytic review of attitudinal and dispositional predictors of organizational citizenship behavior. Personnel Psychology, 48(4), 775-804.

37. Pickering, A. D., Corr, P. J., \& Gray, J. A. (1999). Interactions and reinforcement sensitivity theory: A theoretical analysis of Rusting and Larsen (1997). Personality and Individual Differences, 26(2), 357365.

38. Weiss, H. M., \& Cropanzano, R. (1996). Affective events theory: A theoretical discussion of the structure, causes and consequences of affective experiences at work.

39. Steel, R. P., \& Rentsch, J. R. (1997). The dispositional model of job attitudes revisited: Findings of a 10-year study. Journal of Applied Psychology, 82(6), 873-879.

40. Crewson, P. E. (1997). Public-service motivation: Building empirical evidence of incidence and effect. Journal of Public Administration Research and Theory, 7(4), 499-518.

41. Van Vianen, A. E. M., \& De Dreu, C. K. W. (2001). Personality in teams: Its relationship to social cohesion, task cohesion, and team performance. European Journal of Work and Organizational Psychology, 10(2), 97-120.

42. Peterson, R. D., Smith, D. B., Martorana, P. V., \& Owens, P. D. (2003). The impact of chief executive officer personality on top management team dynamics: One mechanism by which leadership affects organizational performance. Journal of Applied Psychology, 88(5), 795-808.

43. Locke, E. A. (1969). What is job satisfaction? Organizational Behavior and Human Performance, 4(4), 309-336.

44. Goslin, P. A. (2005). Managing employee satisfaction of volunteers in South African sport. African Journal for Physical Health Education, 12, 30-40.

45. Near, J. P., Rice, R. W., \& Hunt, R. G. (1980). The relationship between work and nonwork domains: A review of empirical research. Academy of Management Review, 5(3), 415-429.

46. Wright, T. A., \& Cropanzano, R. (2000). Psychological well-being and job satisfaction as predictors of job performance. Journal of Occupational Health Psychology, 5(1), 84-94.

47. Roznowski, M., \& Hulin, C. L. (1992). The scientific merit of valid measures of general constructs with special reference to job satisfaction and job withdrawal. In C. J. Cranny, P. C. Smith, and E. F. Stone (Eds.), Job Satisfaction: How People Feel About Their Jobs and How It Affects Their Performance. New York: Lexington Books.

48. Ostroff, C. (1992). The relationship between satisfaction, attitudes, and performance: An organizational level analysis. Journal of Applied Psychology, 77(6), 963-974. 
49. Bruce, W. M., \& Blackburn, J. W. (1992). Balancing job satisfaction and performance. Westport, CT: Quorum Books

50. Naff, K. C., \& Crum, J. (1999). Working for America: Does public service motivation make a difference. Review of Public Personnel Administration, 19(4), 5-16.

51. Jordan Investment Commission. (2017). Healthcare - Sector Profile. Amman, Jordan.

52. Ministry of Health. (2017). Annual Report. Amman, Jordan.

53. Goldberg, L. R. (1993). The structure of phenotypic personality traits. American Psychologist, 48(1), 26-34.

54. Liu, C., Borg, I., \& Spector, P. E. (2004). Measurement invariance of the German job satisfaction survey used in a multinational organization: Implications of Schwartz's culture model. Journal of Applied Psychology, 89 (6), 1070-1082.

55. Pearce, J., \& Porter, L. (1986). Employee responses to formal performance appraisal feedback. Journal of Applied Psychology, 71(2), 211-218.

56. Carmeli, A., \& Freund, A. (2004). Work commitment, job satisfaction, and job performance: An empirical investigation. International Journal of Organization Theory and Behavior, 7(3), 289-309.
57. Papadakis, V. M., \& Barwise, P. (2002). How much do CEOs and top managers matter in strategic decision-making? British Journal of Management, 13(0), 83-95.

58. Hu, L., \& Bentler, P. M. (1999). Cutoff criteria for fit indexes in covariance structure analysis: Conventional criteria versus new alternatives. Structural Equation Modeling, 6(1), 1-55.

59. Oshagbemi, T. (2003). Personal correlates of job satisfaction: Empirical evidence from UK universities. International Journal of Social Economics, 30(12): 1210-1232.

60. Sarker, S. J., Crossman, A. \& Chinmeteepituck, P. (2003). The relationships of age and length of service with job satisfaction: An examination of hotel employees in Thailand. Journal of Managerial Psychology, 18(7): 745-758.

61. Dalal, R. S. (2005). A meta-analysis of the relationship between organizational citizenship behavior and counterproductive work behavior. Journal of Applied Psychology, 90(6), 1241-1255.

62. Hardy, G. E., Woods, D., \& Wall, T. D. (2003). The impact of psychological distress on absence from work. Journal of Applied Psychology, 88(2), 306-314.

63. Gelfand, M. J., Erez, M., \& Aycan, Z. (2007). Cross-cultural organizational behavior. Annual Review of Psychology, 58, 479-514. 